\title{
Free Fatty Acid Reduction for Biodiesel Production in Reactive Distillation Column
}

\author{
Pawarat Thummasaneh*, Kulchanat Prasertsit, Sukritthira Ratanawilai,Sirasit Thipkonglat and Thaicom Ongrattana \\ Department of Chemical Engineering, Faculty of Engineering, Prince of Songkla University, Hatyai, Songkhla, 90112 Thailand \\ ${ }^{*}$ Corresponding author
}

\begin{abstract}
To treat high free fatty acid feedstock in biodiesel production, the reduction of free fatty acid by esterification in continuous reactive distillation column was investigated. In this work, ethanol and crude palm oil (CPO) which the molar ratio of ethanol to oil was 8:1 were selected as reactants with Amberlyst15 catalyst and the reaction temperature was $80 \pm 5^{\circ} \mathrm{C}$. The effects of type of reactor, feed location and amount of catalyst were examined experimentally. The result showed that either high amount of catalyst in reactive distillation column increased the efficiency of free fatty acid reduction. Finally, at the same amount of catalyst, feed location at upper part of column yield better reduction free fatty acid than lower part of column.
\end{abstract}

Keywords-amberlyst-15; crude palm oil; esterification; reactive distillation

\section{INTRODUCTION}

In the present, the world has a problem about oil fuels due to high cost and few amount of oil. This causes the research and development in biodiesel as an alternative fuels. Biodiesel is produced from renewable source. In Ministry of Agriculture and Cooperatives (2016) the cost of crude palm oil (CPO) is lower than refined palm oil about 1 time. Therefore it can be selected as a feed stock in order to reduce cost of raw material which is the dominant cost for biodiesel production [1], [2].

However, CPO containing high amount of free fatty acid (FFA) makes rapidly saponification in the reaction of transesterification. Therefore esterification should be done before transesterification. The purpose of this work is to study the effect of type of reactor, amount of catalyst, and feed location on the reduction of FFA in biodiesel production by reactive distillation column (RD) which both chemical reaction and distillation process in a single unit. This technique is lower cost of using alcohol and the operation [3].

\section{MATERIALS AND METHOD}

\section{A. Materials}

Crude palm oil with approximately 5-10\% FFA was acquired from the Specialized R\&D Center for Alternative Energy from Palm Oil and Oil Crops (Thailand). Ethanol $95 \%$ wt was purchased from Merck. Amberlyst-15 was from Sigma Aldrich. Activated carbon was from Qualitech Supply Songkhla, Thailand. Sodium Hydroxide was obtained from Loba Chemie and Phenolphthalein was acquired from QReC.

\section{B. Experimental Setup}

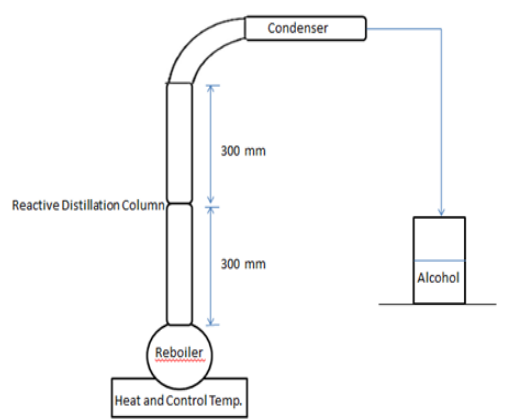

FIGURE I. A SIMPLE REACTIVE DISTILLATION COLUMN

The esterification process was performed in a reactive distillation column: 2 glass tubes in series (each tube has 300 $\mathrm{mm}$ height and $45 \mathrm{~mm}$ inside diameter) with Amberlyst-15 packing. One end side was connected to a reboiler and the other was connected to a condenser. The RD column, reboiler and crude palm oil were preheated up to $80 \pm 5$ oC as a reaction temperature. After reaching the temperature, alcohol and oil (molar ratio of ethanol: CPO is 8:1) were fed to RD column. During continuous reactive distillation column were withdrawn from the reboiler since 60 to $300 \mathrm{~min}$.

\section{Analysis}

The samples were taken from the reactive distillation column. It was washed with distilled water to stop the reaction and separated the alcohol and analyzed by titration method using Sodium Hydroxide $(\mathrm{NaOH})$ and Phenolphthalein indicator.

\section{RESULTS AND DISCUSSION}

\section{A. To Compare Between Reactive Distillation and Batch Reactor}

Figure 2 shows comparison between reactive distillation and batch reactor at $80 \pm 5$ oC, ethanol to oil ratio of $8: 1$ and with catalyst to FFA mass ratio of 0.27 . At the same condition, the highest conversion of FFA was 40.03 in reactive distillation in 2 columns, but as for conversion of FFA was 36.53 in batch reactor. From figure $2 b$ percentage of FFA was rapidly reduced at the first 60 minutes and then the reduction of FFA was slowed until got into steady state around 120 minutes. The result of reactive distillation was highest 
conversion of FFA in reactive distillation columns. It could be reduced FFA better than batch reactor.

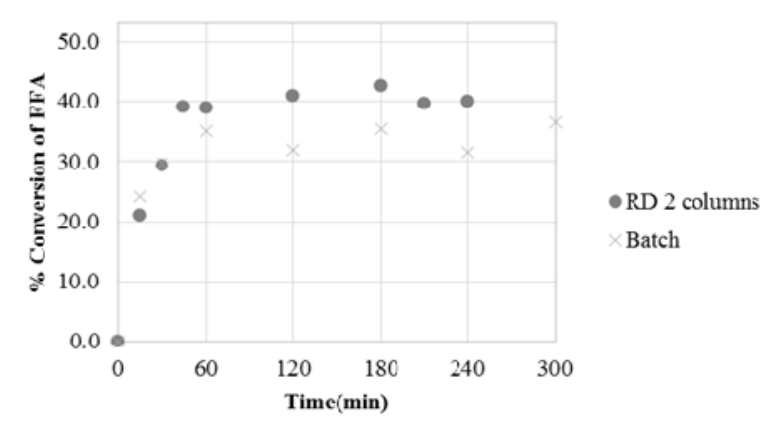

(a)

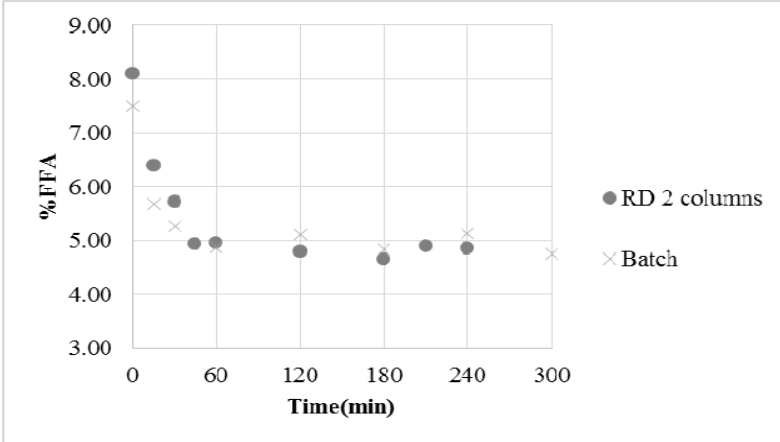

(b)

FIGURE II. FIGURE II. COMPARISON REACTIVE DISTILLATION AND BATCH REACTOR AT 80+5 OC, ETHANOL TO OIL OF 8:1 AND WITH MASS RATIO CATALYST TO FFA OF 0.27

\section{B. Effect of Catalyst to FFA Mass Ratio Reaction}

Figure 3 shows effect of catalyst to FFA mass ratio at $80 \pm 5$ ${ }^{\circ} \mathrm{C}$ and ethanol to oil ratio of 8:1. The mass ratio of catalyst to FFA was increased, the percentage of FFA was changed from 59.10 to 40.03 which was consistent with the results of [4] From the experimental that percentage of FFA decreased sharply in the first 60 minutes and slowed down until got into steady state, but in the time between 180 and 240 minutes in mass ratio of catalyst to FFA equal 0.4 , conversion of FFA was reduced. Probably as a result of the reaction is hydrolysis that a reversible reaction over the esterification. For higher catalyst amount the percentage conversion factor was increased by increasing reaction times. The reduction of FFA was increased with increasing catalyst to FFA mass ratio to 0.4 as shown in fig. $3 \mathrm{~b}$.

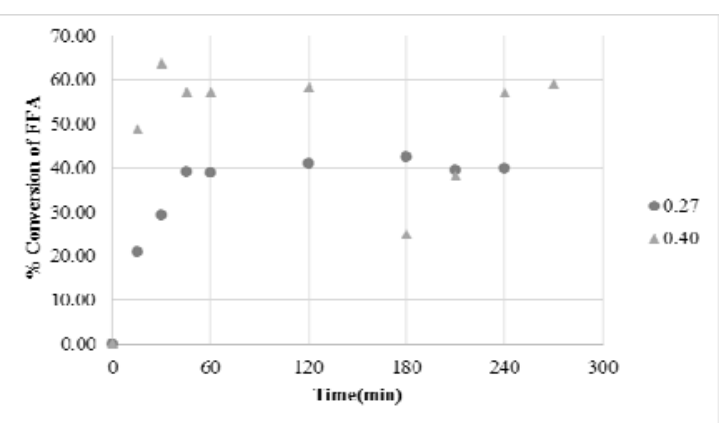

(a)

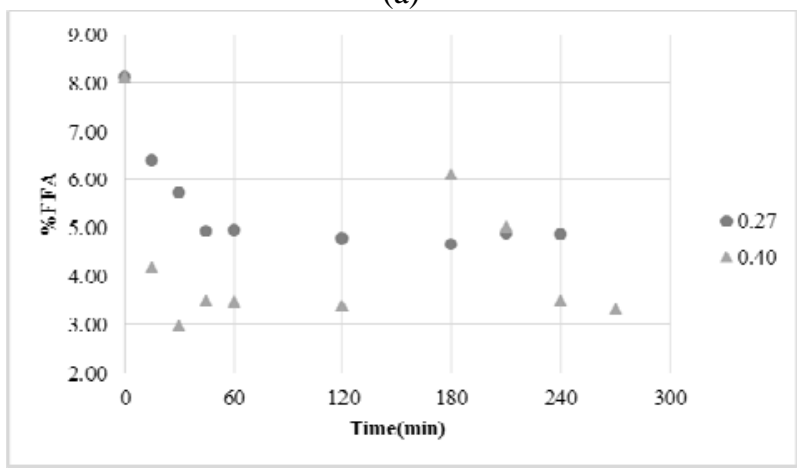

(b)

FIGURE III. FIGURE III. EFFECT OF MASS RATIO OF CATALYST TO

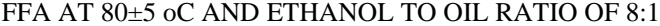

\section{Effect of Feed Location}

Figure 4 shows effect of feed location at $80 \pm 5$ oC, ethanol to oil ratio of $8: 1$ and with mass ratio of catalyst to FFA of 0.27 . Reactant was fed to the upper part of reactive distillation. Thus conversion of FFA was up to 40.03 , but position of reactant was changed to the lower part of reactive distillation that conversion of FFA only 38.25. By the time the first 60 minutes, the percentage of FFA was decreased continuously and got into steady state at 120 minutes.

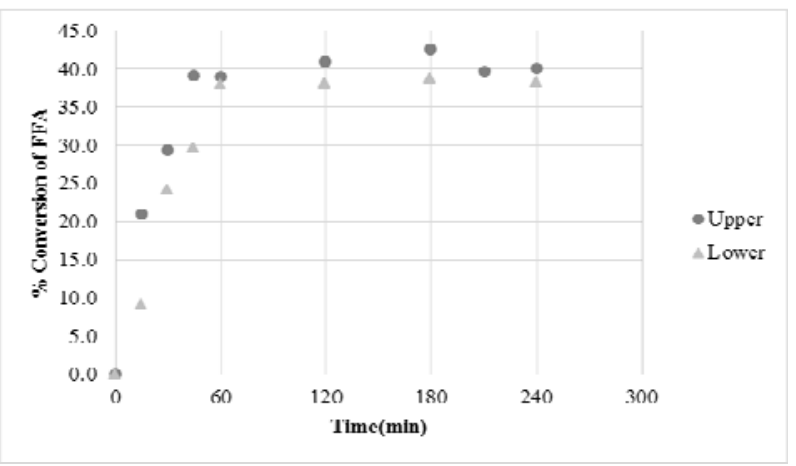

(a)

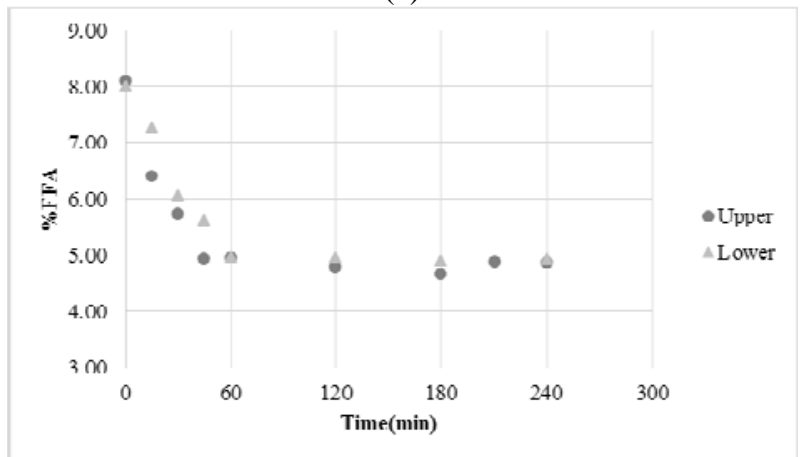

(b)

FIGURE IV. FIGURE IV. EFFECT OF FEED LOCATION AT 80 \pm 5 oC, ETHANOL TO OIL RATIO OF 8:1 AND WITH MASS RATIO OF CATALYST TO FFA OF 0.27 


\section{CONCLUSION}

For reduction of FFA in CPO which biodiesel production by esterification reaction will be better when CPO and ethanol react for a long time in $\mathrm{RD}$ column. The $\mathrm{RD}$ column contains Amberlyst-15, which it could lead to a rapidly reducing FFA reaction because of increase catalysts. In addition, at upper part of column feed efficiently effect a result of reducing FFA process.

\section{ACKNOWLEDGMENT}

The authors thankfully Department of Chemical Engineering and the Specialized R\&D Center for Alternative Energy from Palm Oil and Oil Crops, Prince of Songkla University for support.

\section{REFERENCES}

[1] M. Chai, Q. Tu, M. Lu, and Y. J. Yang. Esterification pretreatment of free acid in biodiesel production from laboratory to industry.” Fuel Processing Technology 125 (2014) 106-113. 2014.

[2] I. S. KIRBASLAR, B. Z. BAYKAL, and U. DRAMUR. Esterication of Acetic Acid with Ethanol Catalysed by an Acidic Ion- Exchange Resin.” Turk J Engin Environ Sci 25 )2001(, 569-577. 2000.

[3] J. M. Marchetti, V. U. Miguel, and A. F. Errazu. "Heterogeneous esterification of oil with high amount of free fatty acids.” Fuel 86 )2007( 906-910. 2006.

[4] N. Ozbay, N. Oktar, and A. N. Tapan. Esterification of free fatty acids in waste cooking oils (WCO): Role of ion-exchange resins. Fule. 87: 17891798. 2008.

[5] R. Pal, T. Sarkar, and Sh. Khasnobis. Amberlyst-15 in organic synthesis.” ARKIVOC 2012 )i( 570-609. 2012.

[6] P. Pornchalermpong and N. Rattanapanon. Food Network Solution. Retrieved November 5, 2015 from the World Wide Web: http://www.foodnetwork solution.com /wiki/1537/free-fatty-acid-.2014.

[7] K. Prasertsit. Plantwide Control of Biodiesel Process. Retreved November 5, 2015 from the World Wide Web: http://elibrary.trf.or.th/ fullP/MRG 4980119/MRG4980119_abstract.pdf. 2014.

[8] K. Prasertsit, Ch. Mueanmas, and Ch. Tongurai. "Transesterification of palm oil with methanol in a reactive distillation column." Chemical Engineering and Processing: Process Intensification 70:21-26. 2013.

[9] S. Siemphakdee. Thai Tapioca Starch Association: Ethanol industrial. Retrieved November 26, 2015 from the World Wide Web: http://www. thaitapiocastarch.org /article24_th.asp. 2011.

[10] The Dow Chemical Company. Dow Water \& Process Solutions. Retrieved November 10, 2015 from the World Wide Web: http://www.dow.com/assets/attachments/business/process_chemicals/am berlyst/amberlyst_15wet/tds/amberlyst_15wet.pdf. 2014.

[11] Ch. Tongurai. PSU Biodiesel: Esterification. Retrieved November 5, 2015 from the World Wide Web: http://portal.psu.ac.th/blog/engbiodiesel/21923. 2014

[12] Ch. Tongurai. PSU Biodiesel: Esterification. Retrieved November 5, 2015 from the World Wide Web: http://share.psu.ac.th/blog/engbiodiesel/21146. 2014

[13] Ch. Tongurai. PSU Biodiesel: Esterification. Retrieved November 5, 2015 from the World Wide Web: http://portal.psu.ac.th/blog/engbiodiesel/21923. 2014. 